Check for updates

Cite this: RSC Adv., 2017, 7, 27755

Received 27th February 2017 Accepted 19th May 2017

DOI: $10.1039 / \mathrm{c} 7 \mathrm{ra02417g}$

rsc.li/rsc-advances

\section{Nitrogen-doped graphene and titanium carbide nanosheet synergistically reinforced epoxy composites as high-performance microwave absorbers}

\begin{abstract}
Yuchang Qing, (DD* Hanyi Nan, Fa Luo and Wancheng Zhou
The electromagnetic (EM) properties of both nitrogen-doped graphene (N-GP) and $\mathrm{Ti}_{3} \mathrm{C}_{2}$ nanosheets as hybrid absorbers were investigated in the frequency range of $2-18 \mathrm{GHz}$. The values and frequency dependencies of EM properties of such hybrid absorbers can be adjusted by the combination of the unique microstructure and dielectric characteristics of the $\mathrm{N}-\mathrm{GP}$ and $\mathrm{Ti}_{3} \mathrm{C}_{2}$ nanosheets. The minimum reflection loss $(R L)$ reaches up to $-52 \mathrm{~dB}$ and the bandwidth below $-10 \mathrm{~dB}$ can be obtained in the frequency range of $10.9-18 \mathrm{GHz}$ with a sample thickness of $1.4 \mathrm{~mm}$. These results suggest that $\mathrm{N}-\mathrm{GP}$ and $\mathrm{Ti}_{3} \mathrm{C}_{2}$ nanosheets as hybrid absorbers are highly promising fillers for dielectric and $\mathrm{EM}$ applications, especially for thin-thickness, broadband absorption microwave absorbers.
\end{abstract}

\section{Introduction}

The unique properties of 2D nanosheets, which are lightweight, flexible and have high mechanical strength, high thermal conductivity, high specific surface area and excellent electronic properties, have enabled rapid development in their fundamental research and practical applications. They can be used in electronics, optoelectronics, catalysis, energy storage devices and so on. ${ }^{1-7}$ More recently, 2D nanosheets with outstanding dielectric properties have received significant investigation in the field of electromagnetic (EM) and microwave absorption due to their corresponding dimensional structures, high specific surface area and clustered defects. ${ }^{8-16}$ Ultrathin graphene (GP) and graphene nanosheets (GNs), with low density, high aspect ratio and high conductivity, exhibit good microwave absorption and indicate the GP and GNs could be very promising microwave absorber. The dielectric properties and microwave absorption performance of few-layered $\mathrm{MoS}_{2}$ nanosheets were reported, and the minimum reflection loss (RL) value of $\mathrm{MoS}_{2}$ nanosheets/wax with $60 \mathrm{wt} \%$ loaded is $-38.42 \mathrm{~dB}$ at a thickness of $2.4 \mathrm{~mm} \cdot{ }^{15} \mathrm{~A}$ thin sample consisting of $10 \mathrm{wt} \%$ $\mathrm{MoS}_{2} / \mathrm{RGO}$ hybrid in the wax matrix exhibited an effective microwave absorption bandwidth of $5.72 \mathrm{GHz}$ at the thickness less than $2.0 \mathrm{~mm} .^{16}$

The MXenes with 2D early transition metal carbides and carbonitrides are produced by selective etching of the A element from the MAX phases. MXenes combine the metallic

State Key Laboratory of Solidification Processing, School of Materials Science and Engineering, Northwestern Polytechnical University, Xi'an 710072, China. E-mail: qtvbgyta@163.com; qingyuchang@nwpu.edu.cn; Fax: +862988494574 conductivity of transition metal carbides with unique morphologies render them strong candidates for many applications..$^{5-7}$ Up to now, few experimental results that exist to date have explored the EM properties of MXenes, which have a wide range of potential applications, such as EM interference shielding, actuators, microwave absorber, capacitors, and photovoltaic. More recently, the RL values of the $\mathrm{Ti}_{3} \mathrm{C}_{2}$ nanosheets filled composites exceeding $-11 \mathrm{~dB}$ (more than $92 \%$ absorption) in the frequency range of $12.4-18 \mathrm{GHz}$ with a thickness of $1.4 \mathrm{~mm}$, suggests that $\mathrm{Ti}_{3} \mathrm{C}_{2}$ nanosheets with unique dielectric properties are highly promising fillers for dielectric and EM applications. ${ }^{17}$

However, single GP or GNs filled composites could not meet the demands of ideal microwave absorbing materials (MAMs) because the intrinsic high permittivity and low permeability of such materials, lead to poor impedance matching and further affect absorbing properties. The effectiveness of a MAM is mainly depended on its EM characteristics, which means the key point to obtain thin-layer broadband GP-filled MAMs is controlling the EM properties of such composites. In order to effectively improve microwave absorptions, attentions have been directed toward adding magnetic and/or dielectric fillers into a matrix, for instance, adding magnetic materials to GPfilled composites to enhance their complex permeability, to satisfy the demand of low reflection over a broad frequency range. ${ }^{14}$ Hybrid absorbers possess the advantages of its individual components and may exhibit new EM properties and functions for practical applications. The components of hybrid absorbers can be chosen from a wide range of materials with versatile morphologie. ${ }^{18}$ Nevertheless, to our best knowledge, investigations on the EM properties and microwave absorption 
performance of nitrogen-doped graphene (N-GP)/ $\mathrm{Ti}_{3} \mathrm{C}_{2}$ nanosheets as hybrids absorbers have yet to report to date.

The dielectric properties and microwave absorption of N-GP and $\mathrm{Ti}_{3} \mathrm{C}_{2}$ nanosheets filled epoxy composites were investigated in the frequency range of $2-18 \mathrm{GHz}$. Attributed to unique microstructure and suitable EM properties of N-GP and $\mathrm{Ti}_{3} \mathrm{C}_{2}$ nanosheets, N-GP and $\mathrm{Ti}_{3} \mathrm{C}_{2}$ nanosheets as hybrid absorbers filled composites have significant development potential to obtain suitable values and frequency dependency of EM properties. The minimum RL value reaches up to $-52 \mathrm{~dB}$ and the bandwidth below $-10 \mathrm{~dB}$ can be obtained in the frequency range of $10.9-18 \mathrm{GHz}$ with a thickness of $1.4 \mathrm{~mm}$, indicates that such hybrid absorbers can be good candidates for fabricating microwave absorbers with thin-thickness, wide bandwidth and enhanced microwave absorption.

\section{Materials and methods}

The N-GP was prepared via a CVD process by using a $20 \mathrm{~nm}$ thick of $\mathrm{Cu}$ film on a Si substrate as the catalyst, and $\mathrm{NH}_{3}$ and $\mathrm{CH}_{4}\left(\mathrm{NH}_{3} / \mathrm{CH}_{4}\right.$ ratios of $\left.1: 1.5\right)$ as the $\mathrm{N}$ source and $\mathrm{C}$ source, respectively. ${ }^{19}$ After growth, the sample was cooled to room temperature under $\mathrm{H}_{2}$ and $\mathrm{Ar}$ ambient. The $\mathrm{Ti}_{3} \mathrm{C}_{2}$ nanosheets were produced by selective etching of the $\mathrm{Al}$ element from $\mathrm{Ti}_{3} \mathrm{AlC}_{2}$ powders. In a typical process, the $\mathrm{Ti}_{3} \mathrm{AlC}_{2}$ powders were immersed in $50 \% \mathrm{HF}$ for $3 \mathrm{~h}$ at room temperature. The resulting suspension was then washed several times using deionized water and centrifuged to separate the powders. The $\mathrm{Ti}_{3} \mathrm{AlC}_{2}$ powders after HF treatment were added into the ethyl alcohol and then ultrasonic treatment for $1 \mathrm{~h}$ to obtain the $\mathrm{Ti}_{3} \mathrm{C}_{2}$ nanosheets. The matrix used in this work is epoxy resin and the cure agent is polyamide resin, which were supplied by XI AN Leeo Technological Co.

In order to determine the characteristic of the composite, four samples containing different contents of $\mathrm{N}-\mathrm{GP}$ and/or $\mathrm{Ti}_{3} \mathrm{C}_{2}$ nanosheets were manufactured and tested. The sample ID was specified by the content of filler. Sample G2, G2T20, G2T30 and T40 indicate a composition consisting of $2 \mathrm{wt} \% \mathrm{~N}-\mathrm{GP}, 2 \mathrm{wt} \% \mathrm{~N}-$ GP and $20 \mathrm{wt} \% \mathrm{Ti}_{3} \mathrm{C}_{2}$ nanosheets, $2 \mathrm{wt} \% \mathrm{~N}-\mathrm{GP}$ and $30 \mathrm{wt} \% \mathrm{Ti}_{3} \mathrm{C}_{2}$ nanosheets, and $40 \mathrm{wt} \% \mathrm{Ti}_{3} \mathrm{C}_{2}$ nanosheets, respectively. Epoxy resin and polyamide resin were mixed in $4: 1$ weight ratio for preparing matrix used in the experiment.

In order to fully achieve the reinforced potential of N-GP and $\mathrm{Ti}_{3} \mathrm{C}_{2}$ nanosheets, a highly homogenized dispersion of the fillers is required. First, the N-GP and/or $\mathrm{Ti}_{3} \mathrm{C}_{2}$ nanosheets were dispersed in acetone using an ultrasonic bath, at room temperature, for $4 \mathrm{~h}$. Then the previously prepared matrix was proportionally weighed and added, followed by stirring at $2000 \mathrm{rpm}$ for $10 \mathrm{~min}$ to have the uniform distribution of N-GP and/or $\mathrm{Ti}_{3} \mathrm{C}_{2}$ nanosheets. In order to reduce the voids, which could detrimentally affect the properties of the final sample, the bubbles should be avoided with the solvent properly evaporated by following steps: the mixture of the resin and absorbers preheated to $60{ }^{\circ} \mathrm{C}$ in a vacuum drying oven to reduce its viscosity, then evaporated acetone and eliminated the entrapped air, which also can avoid the re-aggregation of N-GP and $\mathrm{Ti}_{3} \mathrm{C}_{2}$ nanosheets. Finally, the samples were cured at $120^{\circ} \mathrm{C}$ for $4 \mathrm{~h}$ to obtain well-shaped hard discs.

The morphology of the samples was observed by field emission scanning electron microscopy (FE-SEM) (Model JSM6360, JEOL, Tokyo, Japan) and transmission electron microscopy (TEM) (Model JEM-2100, JEOL, Tokyo, Japan). Raman spectra were recorded on a Renishaw RM 1000 confocal system spectrometer. X-ray photoelectron spectroscopy (XPS) measurements were examined by an XPS spectrometer (ESCALAB250, Thermo, USA). Cylindrical toroidal specimen (out diameter of $7.0 \mathrm{~mm}$ and inner diameter of $3.03 \mathrm{~mm}$ ) were prepared for $\mathrm{EM}$ properties measurement in the frequency range of $2-18 \mathrm{GHz}$, using the $\mathrm{T} / \mathrm{R}$ coaxial line method by a network analyzer (Agilent Technologies E8362B: $10 \mathrm{MHz}$ to 20 $\mathrm{GHz})$.

\section{Results and discussions}

TEM images (Fig. 1a) show the N-GP has a flexible and rumpling morphology, which indicates the N-GP is flexible, and such rumpling comes from the growth process and the cooling process. ${ }^{19}$ The exfoliated $\mathrm{Ti}_{3} \mathrm{C}_{2}$ nanosheets with typical of
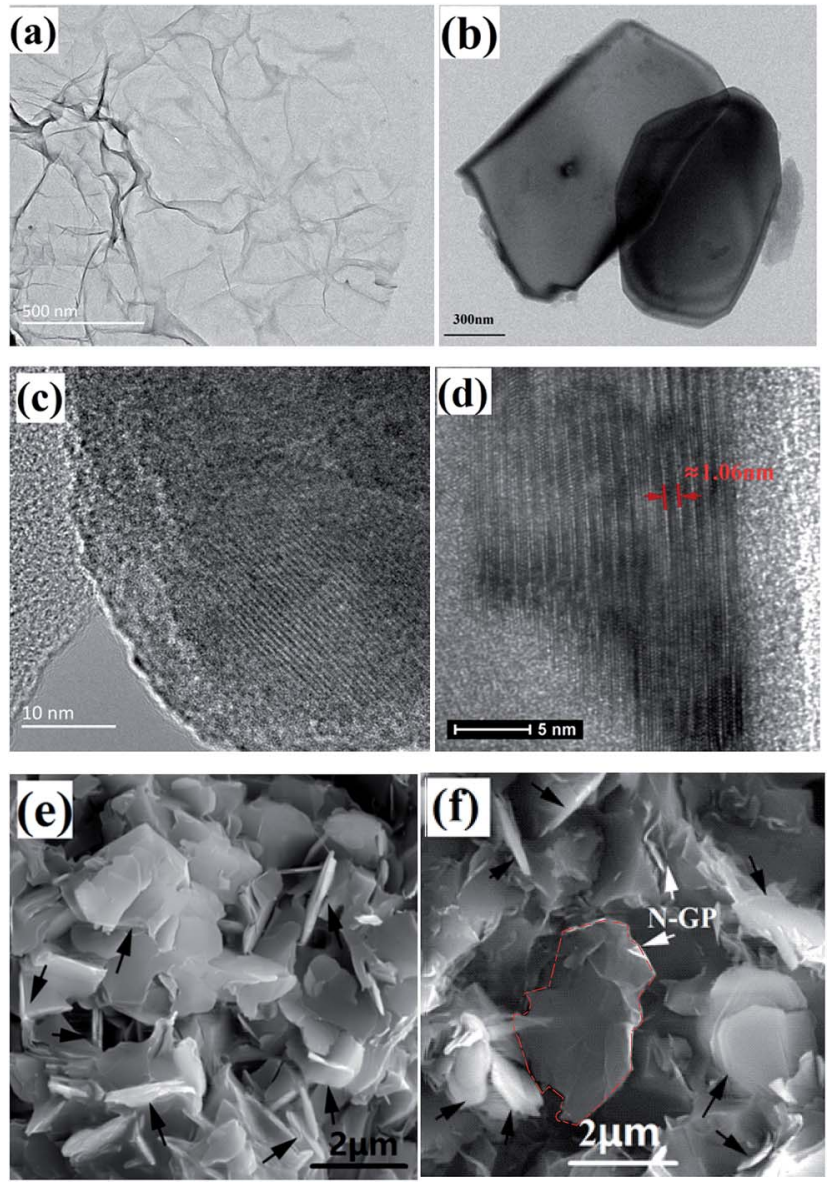

Fig. 1 TEM image of (a) the N-GP and (b-d) TEM image of the exfoliated $\mathrm{Ti}_{3} \mathrm{C}_{2}$ nanosheets. Typical SEM images of the N-GP and/or $\mathrm{Ti}_{3} \mathrm{C}_{2}$ nanosheets filled composites, (e) sample T40 and (f) sample G2T30 (the black arrows for the $\mathrm{Ti}_{3} \mathrm{C}_{2}$ nanosheets). 
MXenes structure were obtained, which clearly confirms the successful exfoliation of individual $\mathrm{Ti}_{3} \mathrm{AlC}_{2}$ particles, as shown in Fig. 1b and c. The HRTEM image reveals the detailed crystalline structure of the $\mathrm{Ti}_{3} \mathrm{C}_{2}$ nanosheets, and the multilayer stacks are comprised of about 16 layers, and the corresponding layer spacing in the $c$-direction is $\sim 10.6 \AA$ (Fig. 1d).

The $\mathrm{Ti}_{3} \mathrm{C}_{2}$ nanosheets, acting as a three-phase particle, are also thought to improve the dispersion of N-GP in the final composite, which can lead to a dramatic improvement of N-GP and $\mathrm{Ti}_{3} \mathrm{C}_{2}$ nanosheets dispersion throughout the matrix. Fig. 1e and $\mathrm{f}$ show the dispersions of $\mathrm{N}-\mathrm{GP}$ and/or $\mathrm{Ti}_{3} \mathrm{C}_{2}$ nanosheets, indicating that the use of ultrasonic treatment and intensely mechanical stirring is an effective way to enhance the dispersion N-GP and $\mathrm{Ti}_{3} \mathrm{C}_{2}$ nanosheets throughout the matrix.

Typical D band (from defect and amorphous carbon) and $\mathrm{G}$ band (from graphite) are detected at $\sim 1352$ and $\sim 1578 \mathrm{~cm}^{-1}$ for the N-GP, as shown in Fig. 2. The ratio between the intensities of the $\mathrm{D}$ and $\mathrm{G}$ bands $\left(I_{\mathrm{D}} / I_{\mathrm{G}}\right)$ is, about 0.94 for N-GP, considered to be the ratio of structural defects and domain size in graphitic materials. There are many factors, which can affect the position of the $\mathrm{G}$ band, such as doping, layer numbers, defects, strains, substrate, etc. ${ }^{20}$ The shift of the $\mathrm{G}$ band and high value of $I_{\mathrm{D}} / I_{\mathrm{G}}$ for the N-GP indicates $\mathrm{N}$ doping break the $\mathrm{sp}^{2}$ carbon domains in the $2 \mathrm{D}$ hexagonal structure to form $\mathrm{sp}^{3}$ defect and introduce large amount of topological defects. The observation of $\mathrm{N}$ doping causes a downshift of the $\mathrm{G}$ band is also similar to those reported N-doped CNTs and N-GP. ${ }^{19}$ Raman spectra of $\mathrm{Ti}_{3} \mathrm{C}_{2}$ after $\mathrm{HF}$ treatment are also shown in Fig. 2. Compared with $\mathrm{Ti}_{3} \mathrm{AlC}_{2},{ }^{6}$ peaks assigned to $\mathrm{Al}-\mathrm{Ti}$ vibrations vanished after treatment, while peaks involve only $\mathrm{Ti}-\mathrm{C}$ vibrations merged, broadened, downshifted, and the peak intensities are also

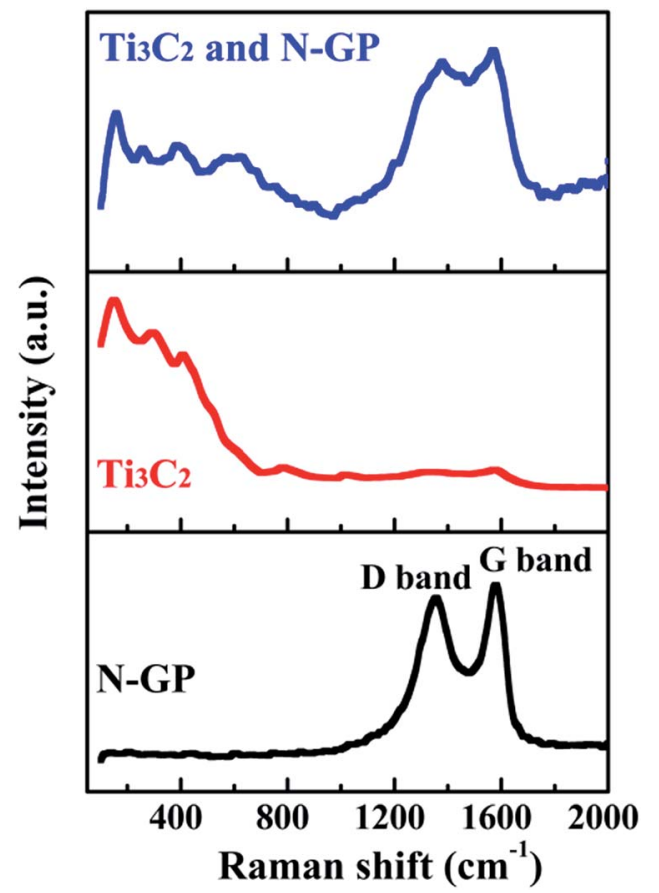

Fig. 2 Raman spectra of the N-GP, $\mathrm{Ti}_{3} \mathrm{C}_{2}$ nanosheets, and the N-GP/ $\mathrm{Ti}_{3} \mathrm{C}_{2}$ nanosheets.
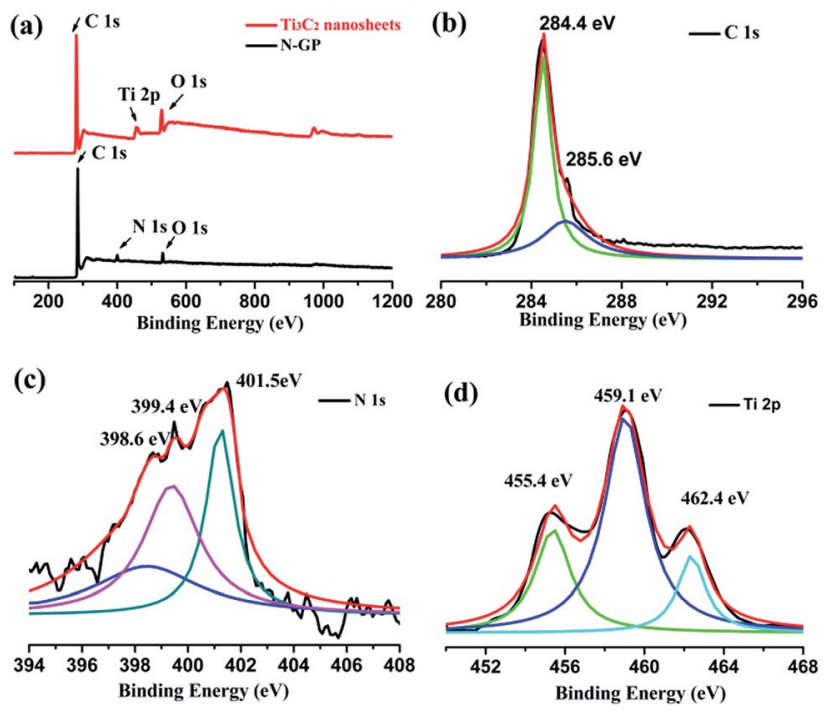

Fig. 3 (a) XPS spectra of the G-NP and $\mathrm{Ti}_{3} \mathrm{C}_{2}$ nanosheets. (b) Highresolution XPS C 1s spectrum and (c) XPS N 1s spectrum of the G-NP. (d) High-resolution $\mathrm{Ti} 2 \mathrm{p}$ spectra of $\mathrm{Ti}_{3} \mathrm{C}_{2}$ nanosheets.

much reduced. Such changes observed in Raman spectra of $\mathrm{Ti}_{3} \mathrm{C}_{2}$ after $\mathrm{HF}$ treatment confirms the loss of $\mathrm{Al}$ from the structure, and are in agreement with the previously reported Raman spectra of the $\mathrm{Ti}_{3} \mathrm{C}_{2}$ nanosheets prepared from $\mathrm{Ti}_{3} \mathrm{AlC}_{2}$ powders with HF treatment. ${ }^{5-7}$

The XPS spectra of G-NP confirm the $\mathrm{N}$ doping of the graphene, the peaks at $284.4,401.5$, and $532.4 \mathrm{eV}$ correspond to $\mathrm{C}$ $1 \mathrm{~s}$ of $\mathrm{sp}^{2} \mathrm{C}, \mathrm{N} 1 \mathrm{~s}$ of the doped $\mathrm{N}$, and $\mathrm{O} 1 \mathrm{~s}$ of the absorbed oxygen, respectively, and the atomic percentage of $\mathrm{N}$ in the sample is about 5.6 at\%. Oxygen can be included due to exposure to the air. No extra peaks except $\mathrm{C}, \mathrm{N}$ and $\mathrm{O}$ were observed, indicating the high purity of the product. The main peak at $284.4 \mathrm{eV}$ corresponds to the graphite-like $\mathrm{sp}^{2} \mathrm{C}$, indicating most of the $\mathrm{C}$ atoms in the $\mathrm{N}$-doped graphene are arranged in a conjugated honeycomb lattice. The small peaks at $285.6 \mathrm{eV}$ reflect different bonding structure of the $\mathrm{C}-\mathrm{N}$ bonds, such as the $\mathrm{N}-\mathrm{sp}^{2} \mathrm{C}$ bonds, and would originate from substitution of the $\mathrm{N}$ atoms, defects or the edge of the graphene sheets. ${ }^{20}$ The high resolution XPS spectrum of $\mathrm{N}$ 1s (Fig. 3c) can be resolved into three bonds, which locate at 398.6, 399.4 and $401.5 \mathrm{eV}$, respectively. The main peak at $401.5 \mathrm{eV}$ is associated to the graphitic $\mathrm{N}$ bonding, which refers to the $\mathrm{N}$ atoms replacing the $\mathrm{C}$ atoms inside of the graphene layers, and is in good agreement with the spectral feature of reported CVD N-GP. ${ }^{19}$ The small peaks at 398.6 and $399.4 \mathrm{eV}$ correspond to pyridinic $\mathrm{N}$ and pyrrolic $\mathrm{N}$, respectively. They refer to the $\mathrm{N}$ atoms which are located in a $\pi$ conjugated system and contribute to the $\pi$ system with one or two p-electrons, respectively. The Ti 2p XPS results of $\mathrm{Ti}_{3} \mathrm{C}_{2}$ nanosheets exhibit the four predominant peaks at $\sim 455.4,459.1$, and $462.4 \mathrm{eV}$, which correspond to the $\mathrm{Ti}-\mathrm{O}$ $\left(2 \mathrm{p}^{1}\right)$, Ti-O $\left(2 \mathrm{p}^{3}\right)$, and $\mathrm{Ti}-\mathrm{C}\left(2 \mathrm{p}^{3}\right)$, respectively, as shown in Fig. 3d. The presence of $\mathrm{Ti}-\mathrm{C}$ and $\mathrm{Ti}-\mathrm{O}$ bonds was evident from both spectra, indicating the formation of $\mathrm{Ti}_{3} \mathrm{C}_{2}$ MXenes after treatment. The $O 1 \mathrm{~s}$ main signal (at $\approx 530.1 \mathrm{~cm}^{-1}$ ) suggest the 
presence of an $\mathrm{OH}$ group. ${ }^{21}$ As mentioned above, defects and functional groups existed for both of N-GP and $\mathrm{Ti}_{3} \mathrm{C}_{2}$ nanosheets, which can induce dielectric polarization relaxation and group's electronic dipole polarization relaxation, which is believed to be favorable for microwave absorption performance.

Interactions between the microwave-absorber filled composites and EM waves in the microwave frequency band can be expressed by relative complex permittivity $\left(\varepsilon^{*}=\varepsilon^{\prime}-\mathrm{j} \varepsilon^{\prime \prime}\right)$ and complex permeability $\left(\mu^{*}=\mu^{\prime}-\mathrm{j} \mu^{\prime \prime}\right)$. For the relative complex permittivity of the absorber, the real part of the relative complex permittivity $\left(\varepsilon^{\prime}\right)$ is proportional to the quantity of the electric charges stored on the surface when the composite is under an applied electric field. The imaginary part of the relative complex permittivity $\left(\varepsilon^{\prime \prime}\right)$ accounts for the energy loss via dissipative mechanisms of the composites. ${ }^{22-28}$ Fig. 4 shows the frequency dependencies of the $\varepsilon^{\prime}$ and $\varepsilon^{\prime \prime}$ of the epoxy composites filled with $\mathrm{N}-\mathrm{GP}$ and/or $\mathrm{Ti}_{3} \mathrm{C}_{2}$ nanosheets as absorber. Both the values of $\varepsilon^{\prime}$ and $\varepsilon^{\prime \prime}$ of the $2 \mathrm{wt} \% \mathrm{~N}-\mathrm{GP}$ and $30 \mathrm{wt} \% \mathrm{Ti}_{3} \mathrm{C}_{2}$ nanosheets-filled composites in the measured frequency range, about 39.2-11.7 and 9.5-4.5, respectively, are much higher than those of $40 \mathrm{wt} \%$ $\mathrm{Ti}_{3} \mathrm{C}_{2}$ nanosheets-filled composites, about 18.0-9.1 and 6.2-3.6, respectively. The value of $\varepsilon^{\prime}$ is an expression of the polarization of a material (consisted of interface and orientation polarization) under the EM field. ${ }^{29}$ It is found that using N-GP and $\mathrm{Ti}_{3} \mathrm{C}_{2}$ nanosheets as hybrid absorber result in a significant enhancement of $\varepsilon^{\prime}$ of such composites. A large quantity of surface electric charges and defects can be created by using the N-GP
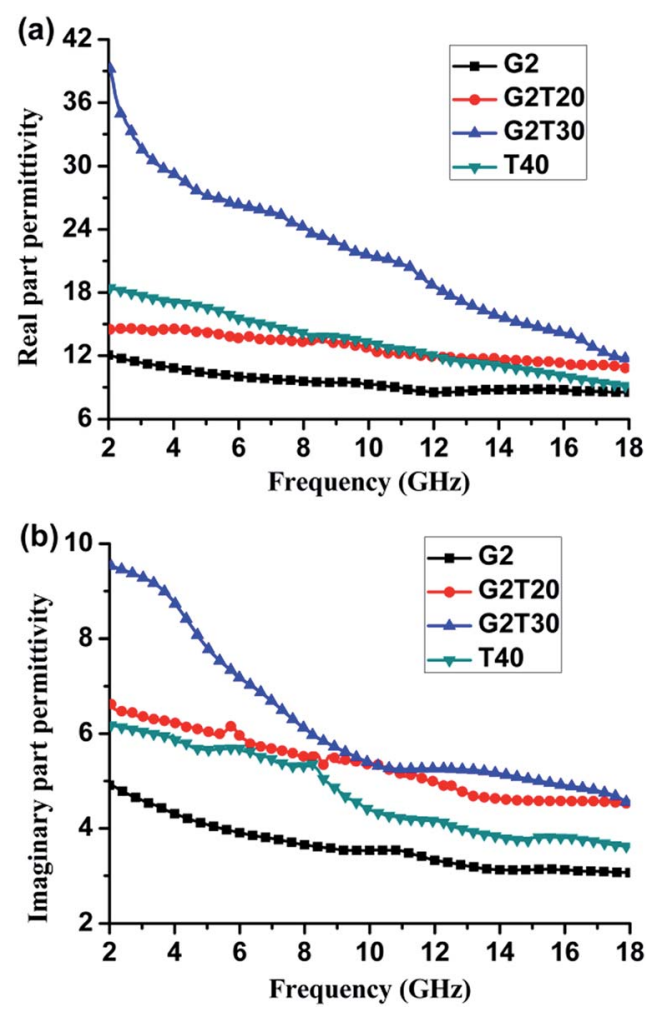

Fig. 4 Frequency dependencies of the (a) real and (b) imaginary part of the relative complex permittivity of the $\mathrm{N}-\mathrm{GP}$ and $\mathrm{Ti}_{3} \mathrm{C}_{2}$ nanosheets filled epoxy composites in the frequency range of $2-18 \mathrm{GHz}$. and $\mathrm{Ti}_{3} \mathrm{C}_{2}$ nanosheets as absorbers, which are obtained by an aggressive exfoliation process. ${ }^{17}$ The enhanced number of interfaces between $\mathrm{N}-\mathrm{GP}$ and $\mathrm{Ti}_{3} \mathrm{C}_{2}$ nanosheets with the epoxy matrix result in more electron relaxation polarization and interfacial polarization, thus, it should be possible to obtain the higher values of $\varepsilon^{\prime}$ for the N-GP and $\mathrm{Ti}_{3} \mathrm{C}_{2}$ nanosheets filled composites. A large number of microcapacitors between the $\mathrm{N}$ GP and $\mathrm{Ti}_{3} \mathrm{C}_{2}$ nanosheets were formed due to their unique $2 \mathrm{D}$ microstructure, which results in the increasement of the polarization mechanisms and also is responsible for the enhancement of the value of $\varepsilon^{\prime}$. Moreover, the $\varepsilon^{\prime}$ of the N-GP and $\mathrm{Ti}_{3} \mathrm{C}_{2}$ nanosheets filled composites (sample G2T30) shows an apparent decrease with increasing frequency than that of the single N-GP or $\mathrm{Ti}_{3} \mathrm{C}_{2}$ nanosheets filled composites.

The values of $\varepsilon^{\prime \prime}$ mainly depend on two different factors in the microwave frequency range: relaxation and/or polarization phenomenon and electrical conductivity, which can be expressed by the equation: $\varepsilon=\varepsilon_{\text {relax }}^{\prime \prime}+\sigma /\left(\omega \varepsilon_{0}\right)$, where $\varepsilon_{\text {relax }}^{\prime \prime}$ is the relaxation polarization in this case, $\sigma$ is the electrical conductivity, $\varepsilon_{0}$ is the dielectric constant in vacuum, and $\omega$ is the angular frequency. ${ }^{30}$ Thus, the $\varepsilon^{\prime \prime}$ mainly characterizes the capacity of dielectric loss and is determined by the electrical conductivity and relaxation polarization of such composites. The values of $\varepsilon^{\prime \prime}$ of the sample G2T20 (2 wt\% N-GP and $20 \mathrm{wt} \%$ $\mathrm{Ti}_{3} \mathrm{C}_{2}$ nanosheets filled composites) are slightly higher than that of the sample $\mathrm{T} 40$ ( $40 \mathrm{wt} \% \mathrm{Ti}_{3} \mathrm{C}_{2}$ nanosheets filled composites), as shown in Fig. 4b. Obviously, the high value of $\varepsilon^{\prime \prime}$ of sample G2T20 is caused by added N-GP, which comes from the low resistivity of N-GP and the formation of the N-GP conducting network. Simultaneously, interfacial polarization and the associated relaxation may be also making great contributions to improvement of $\varepsilon^{\prime \prime}$ value, due to the combination of N-GP and $\mathrm{Ti}_{3} \mathrm{C}_{2}$ nanosheets. Additionally, the existence of polar functional groups and defects remaining in the N-GP and $\mathrm{Ti}_{3} \mathrm{C}_{2}$ nanosheets can also increase the dipolar polarization in the composites, which will contribute to the dielectric loss by presenting a higher $\varepsilon^{\prime \prime}$ value. The microstructure and polarization of the N-GP and $\mathrm{Ti}_{3} \mathrm{C}_{2}$ nanosheets affect the formation of the microcapacitors network and the evolution of conductive/ dielectric loss, which can influence the values and frequency dependencies of both $\varepsilon^{\prime}$ and $\varepsilon^{\prime \prime} \cdot{ }^{31-34}$ Therefore, it is reasonable to consider the enhanced values of $\varepsilon^{\prime}$ and $\varepsilon^{\prime \prime}$ due to the unique microstructure, larger internal boundary layer capacitance, and defects in such N-GP and $\mathrm{Ti}_{3} \mathrm{C}_{2}$ nanosheet-filled composites, which are the most significant factors affecting the EM properties and absorption performance of such composites. Results of EM properties show that using both N-GP and $\mathrm{Ti}_{3} \mathrm{C}_{2}$ nanosheets as absorber can change the values and frequency dependencies of both $\varepsilon^{\prime}$ and $\varepsilon^{\prime \prime}$ in the measured frequency range. Furthermore, the values of $\varepsilon^{\prime}$ and $\varepsilon^{\prime \prime}$ of the N-GP and $\mathrm{Ti}_{3} \mathrm{C}_{2}$ nanosheets filled composite also can be tuned by an adjustment of the nature and content of the filler particles, which offer multiple degrees of freedom to tune overall effective permittivity and play a key role in improving the EM absorption performance.

The main requirements for the EM absorbers are expected to have strong microwave absorption in a wide frequency range, 

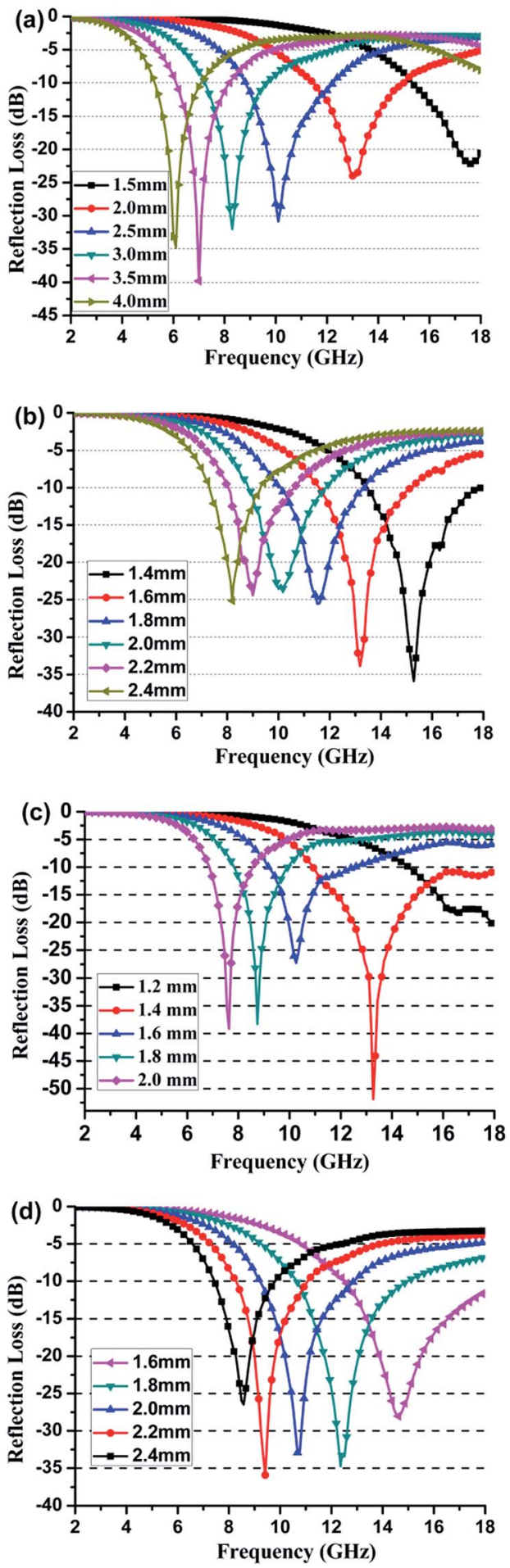

Fig. 5 Frequency dependent of the $\mathrm{RL}$ of composite containing different content of $\mathrm{N}-\mathrm{GP}$ and/or $\mathrm{Ti}_{3} \mathrm{C}_{2}$ nanosheets, (a) sample G2, (b) sample G2T20, (c) sample G2T30 and (d) sample T40.

with lightweight and thinner thickness. High RL values of the MAMs over a broad frequency range can be common achieved by the appropriate value and frequency dependence of EM properties. ${ }^{35-40}$ Fig. 5 shows the values of RL of the N-GP and/or $\mathrm{Ti}_{3} \mathrm{C}_{2}$ nanosheets filled composites in the frequency of 2-18
$\mathrm{GHz}$, which was calculated based on the measured values of $\varepsilon^{\prime}$ and $\varepsilon^{\prime \prime}$ according to the transmission line theory. The real and imaginary part of relative complex permeability of N-GP and/or $\mathrm{Ti}_{3} \mathrm{C}_{2}$ nanosheets is almost 1 and 0 in the whole measured frequency range, due to the weak magnetic characteristics of both N-GP and/or $\mathrm{Ti}_{3} \mathrm{C}_{2}$ nanosheets.

Therefore, the values of $\mathrm{RL}$ of the N-GP and/or $\mathrm{Ti}_{3} \mathrm{C}_{2}$ nanosheets filled composites are mainly depended on the values of $\varepsilon^{\prime}$ and $\varepsilon^{\prime \prime}$ and dielectric loss. As shown in Fig. 5a, the RL values of the $2 \mathrm{wt} \% \mathrm{~N}-\mathrm{GP}$ filled composites can only obtain some high $\mathrm{RL}$ value under larger thickness at specific single frequencies, i.e. the minimum value of $\mathrm{RL}$ is about $-31 \mathrm{~dB}$ and the absorption bandwidth $\leq-10 \mathrm{~dB}$ is about $3.3 \mathrm{GHz}$ (range from 8.9 to $12.2 \mathrm{GHz}$ ) with a sample thickness of $2.5 \mathrm{~mm}$. Furthermore, the absorption bandwidth of $2 \mathrm{wt} \% \mathrm{~N}-\mathrm{GP}$ filled composite is narrow at each single thickness when the composite thickness range from 1.5 to $4 \mathrm{~mm}$. Compared with the RL values of the $2 \mathrm{wt} \% \mathrm{~N}$-GP filled composites, the $40 \mathrm{wt} \%$ $\mathrm{Ti}_{3} \mathrm{C}_{2}$ nanosheets filled composites obtain some high RL under thinner thickness, i.e., the minimum $\mathrm{RL}$ is about $-33 \mathrm{~dB}$ and the absorption bandwidth $\leq-10 \mathrm{~dB}$ is about $3.7 \mathrm{GHz}$ (range from 9.2 to $12.9 \mathrm{GHz}$ ) with a sample thickness of $2.0 \mathrm{~mm}$. Compared with the single absorber (N-GP or $\mathrm{Ti}_{3} \mathrm{C}_{2}$ nanosheets) filled composites, the composites filled with N-GP and $\mathrm{Ti}_{3} \mathrm{C}_{2}$ nanosheets, especially for sample G2T30, had much high RL values, wide absorption bandwidth and thin-thickness, the minimum $\mathrm{RL}$ reaches up to $-52 \mathrm{~dB}$ with the absorption bandwidth $\leq-10 \mathrm{~dB}$ is about $7.1 \mathrm{GHz}$ (range from 10.9 to 18 $\mathrm{GHz}$ ) under a thickness of $1.4 \mathrm{~mm}$. A detailed comparison of the minimum $\mathrm{RL}$ value and absorption bandwidth of N-GP and/or $\mathrm{Ti}_{3} \mathrm{C}_{2}$ nanosheets filled composites and other representative 2D nanosheets filled composites are summarized in the Table 1. It is obviously indicate that $\mathrm{N}-\mathrm{GP}$ and $\mathrm{Ti}_{3} \mathrm{C}_{2}$ nanosheets filled MAMs with high minimum RL value, wider absorption bandwidth and thin-thickness than those reported single layer MAMs.

The absorption frequency ranges and corresponding thicknesses of the MAMs were two key factors for EM applications, and many results show that it is quite a challenge to obtain good absorption performance and thin-thickness at the same time. $^{\mathbf{4 1 - 4 7}}$

Interesting, the RL values of sample were enhanced while the corresponding optimal thickness was decreased for the N-GP and $\mathrm{Ti}_{3} \mathrm{C}_{2}$ nanosheets filled composites. Firstly, the unique microstructure and extremely high defects of the N-GP and $\mathrm{Ti}_{3} \mathrm{C}_{2}$ nanosheets may provide more dielectric polarization induce by the EM wave, which have a significant contribution towards improving both $\varepsilon^{\prime}$ and $\varepsilon^{\prime \prime}$ under lower absorber content. The improved $\varepsilon^{\prime}$ and $\varepsilon^{\prime \prime}$ of the N-GP and $\mathrm{Ti}_{3} \mathrm{C}_{2}$ nanosheets-filled composites showed in Fig. $4 \mathrm{a}$ is generally considered as a significant factor on the dielectric properties and corresponding microwave absorption performances. ${ }^{44}$ Secondly, the extreme thinness and high specific surface area of N-GP and $\mathrm{Ti}_{3} \mathrm{C}_{2}$ nanosheets could increase the propagation paths for the incident waves inside the samples. The corrugated N-GP and $\mathrm{Ti}_{3} \mathrm{C}_{2}$ nanosheets may scattered the EM waves with multiple internal reflection modes are also key point for the 
Table 1 Comparison of values of RL of the N-GP and $\mathrm{Ti}_{3} \mathrm{C}_{2}$ nanosheets filled composites and typical reported 2D nanosheets filled composites in recent literatures

\begin{tabular}{lllc}
\hline Absorber and content & $\begin{array}{l}\text { Thickness } \\
(\mathrm{mm})\end{array}$ & $\begin{array}{l}\text { Minimum RL } \\
\text { value (dB) }\end{array}$ & $\begin{array}{l}\text { Bandwidth RL } \\
<-10 \mathrm{~dB}(\mathrm{GHz})\end{array}$ \\
\hline $2 \mathrm{wt} \% \mathrm{~N}-\mathrm{GP}+30 \mathrm{wt} \% \mathrm{Ti}_{3} \mathrm{C}_{2}$ nanosheets & 1.4 & -52 & $10.9-18$ \\
$50 \mathrm{wt} \% \mathrm{FeCo} / \mathrm{GP}$ & 2.5 & -40.2 & $7.6-12.1$ \\
$60 \mathrm{wt} \% \mathrm{MoS}_{2}$ nanosheets & 2.2 & -47.8 & $11-15.5$ \\
$60 \mathrm{wt} \% \mathrm{MoS}_{2}$ nanosheets & 2.4 & -38.4 & $9.6-13.8$ \\
$10 \mathrm{wt} \% \mathrm{MoS}_{2} /$ reduced GO & 1.9 & -26 & $12.3-18$ \\
$50 \mathrm{wt} \% \mathrm{Ti}_{3} \mathrm{C}_{2}$ nanosheets & 1.4 & -17 & $12.4-18$ \\
$50 \mathrm{wt} \%$ annealed $\mathrm{Ti}_{3} \mathrm{C}_{2}$ MXenes & 1.85 & -45 & $9.6-12.4$
\end{tabular}

enhancement of the values of RL. ${ }^{45}$ Moreover, the proper values and frequency dependencies of $\varepsilon^{\prime}$ and $\varepsilon^{\prime \prime}$ also lead to the reduction of optimal thickness and enhanced absorption of $\mathrm{N}$ GP and $\mathrm{Ti}_{3} \mathrm{C}_{2}$ nanosheets-filled composites. These results indicate the enhancement of microwave absorption is associated with the suitable values and frequency dependence of dielectric properties, which results from the unique microstructure, content and EM characteristic of the fillers by combining advantages of the N-GP and $\mathrm{Ti}_{3} \mathrm{C}_{2}$ nanosheets. Thus, the enhanced EM wave absorption properties result from the proper complementarity between the appropriate values and frequency dependencies of the $\varepsilon^{\prime}$ and $\varepsilon^{\prime \prime}$ of such MAMs.

The values and frequency dependencies of the $\varepsilon^{\prime}$ and $\varepsilon^{\prime \prime}$ of such N-GP and $\mathrm{Ti}_{3} \mathrm{C}_{2}$ nanosheets-filled composites can also be further optimized by changing the N-GP and/or $\mathrm{Ti}_{3} \mathrm{C}_{2}$ nanosheets content. These results indicate that N-GP and $\mathrm{Ti}_{3} \mathrm{C}_{2}$ nanosheets-filled composites with enhanced microwave absorption and thin-thickness can be obtained simply by optimizing the content, composition and dielectric properties of the absorber. Most importantly, the N-GP and $\mathrm{Ti}_{3} \mathrm{C}_{2}$ nanosheetsfilled composites developed here could act as thin-layer MAMs with wideband and enhanced microwave absorption, and can be simply applied to the industrial scale.

\section{Conclusions}

N-GP and $\mathrm{Ti}_{3} \mathrm{C}_{2}$ nanosheets filled composites with high microwave absorption were prepared. The N-GP and $\mathrm{Ti}_{3} \mathrm{C}_{2}$ nanosheets filled absorbing materials with enhanced values of $\varepsilon^{\prime}$ and $\varepsilon^{\prime \prime}$ is mainly due to their the unique microstructure and extremely high defects of the N-GP and $\mathrm{Ti}_{3} \mathrm{C}_{2}$ nanosheets, larger internal boundary layer capacitance, and the formation of the microcapacitors network and the evolution of conductive/dielectric loss. Both the values of $\varepsilon^{\prime}$ and $\varepsilon^{\prime \prime}$ of the N-GP and $\mathrm{Ti}_{3} \mathrm{C}_{2}$ nanosheets filled composite can be tuned by an adjustment of the nature and content of the filler particles, which improved the EM absorption performance. The minimum RL of sample G2T30 reaches up to $-52 \mathrm{~dB}$ with the absorption bandwidth $\leq-10 \mathrm{~dB}$ is about $7.1 \mathrm{GHz}$ (range from 10.9 to $18 \mathrm{GHz}$ ) under a thickness of $1.4 \mathrm{~mm}$. Therefore, the N-GP and $\mathrm{Ti}_{3} \mathrm{C}_{2}$ nanosheets-filled composites developed here could act as thinlayer MAMs with wideband and enhanced microwave absorption.

\section{Acknowledgements}

This his work was financially supported by National Natural Science Foundation of China (No. 51402239), State Key Laboratory of Solidification Processing (NWPU), China (Grant No. KP201422 and KP201604).

\section{Notes and references}

1 A. K. Geim, Science, 2009, 324, 1530.

2 J. N. Coleman, M. Lotya, A. O'Neill, S. D. Bergin, P. J. King, U. Khan, et al., Science, 2011, 331, 568.

3 S. Z. Butler, S. M. Hollen, L. Cao, Y. Cui, J. A. Gupta, H. R. Gutiérrez, et al., ACS Nano, 2013, 7, 2898.

4 V. Nicolosi, M. Chhowalla, M. G. Kanatzidis, M. S. Strano and J. N. Coleman, Science, 2013, 340, 1226419.

5 M. Naguib, O. Mashtalir, J. Carle, V. Presser, J. Lu, L. Hultman, et al., ACS Nano, 2012, 6, 1322.

6 M. Naguib, M. Kurtoglu, V. Presser, J. Lu, J. Niu, M. Heon, et al., Adv. Mater., 2011, 23, 4248.

7 M. Naguib, V. N. Mochalin, M. W. Barsoum and Y. Gogotsi, Adv. Mater., 2013, 26, 992.

8 Y. C. Qing, Q. L. Wen, F. Luo and W. C. Zhou, J. Mater. Chem. C, 2016, 4, 4853.

9 Y. C. Qing, Q. L. Wen, F. Luo, W. C. Zhou and D. M. Zhu, J. Mater. Chem. C, 2016, 4, 371.

10 X. Li, J. Feng, Y. Du, J. Bai, H. Fan, H. Zhang, et al., J. Mater. Chem. A, 2015, 3, 5535.

11 X. H. Liang, X. M. Zhang, W. Liu, D. M. Tang, B. S. Zhang and G. B. Ji, J. Mater. Chem. C, 2016, 4, 6816.

12 H. Yang, M. Cao, Y. Li, H. Shi, Z. Hou, X. Fang, et al., Adv. Opt. Mater., 2014, 2, 214.

13 M. S. Cao, X. X. Wang, W. Q. Cao and J. Yuan, J. Mater. Chem. C, 2015, 3, 6589.

14 Y. C. Qing, D. D. Min, Y. Y. Zhou, F. Luo and W. C. Zhou, Carbon, 2015, 86, 98.

15 M. Q. Ning, M. M. Lu, J. B. Li, Z. Chen, Y. K. Dou, C. Z. Wang, et al., Nanoscale, 2015, 7, 15734.

16 Y. F. Wang, D. L. Chen, X. Yin, P. Xu, F. Wu and M. He, ACS Appl. Mater. Interfaces, 2015, 7, 26226.

17 Y. C. Qing, W. C. Zhou, F. Luo and D. M. Zhu, Ceram. Int., 2016, 42, 16412.

18 B. Aïssa, A. Ali, K. A. Mahmoud, T. Haddad and M. Nedil, Appl. Phys. Lett., 2016, 109, 043109. 
19 D. C. Wei, Y. Q. Liu, Y. Wang, H. L. Zhang, L. P. Huang and G. Yu, Nano Lett., 2009, 9, 1752.

20 J. Feng, F. Z. Pu, Z. X. Li, X. H. Li, X. Y. Hu and J. T. Bai, Carbon, 2016, 104, 214.

21 M. K. Han, X. W. Yin, H. Wu, Z. X. Hou, C. Q. Song, X. L. Li, et al., ACS Appl. Mater. Interfaces, 2016, 8, 21011.

22 Q. Zeng, X. Xiong, P. Chen, Q. Yu, Q. Wang, R. Wang and H. Chu, J. Mater. Chem. C, 2016, 4, 10518.

23 L. B. Kong, Z. W. Li, L. Liu, R. Huang, M. Abshinova, Z. H. Yang, et al., Int. Mater. Rev., 2013, 58, 203.

24 V. M. H. Ng, H. Huang, K. Zhou, P. Lee, W. Que, J. Z. Xu and L. B. Kong, J. Mater. Chem. A, 2017, 5, 3039.

25 Y. C. Qing, W. C. Zhou, F. Luo and D. M. Zhu, Carbon, 2010, 4, 84074.

26 X. L. Zheng, J. Feng, Y. Zong, H. Miao, X. Y. Hu, J. T. Bai and X. H. Li, J. Mater. Chem. C, 2015, 3, 4452.

27 C. Brosseau, J. Appl. Phys., 2002, 91, 3197.

28 Y. C. Qing, W. C. Zhou, F. Luo and D. M. Zhu, J. Mater. Chem. C, 2013, 1, 536.

29 C. Brosseau, P. Quéffélec and P. Talbot, J. Appl. Phys., 2001, 89, 4532.

30 X. Li, H. Yi, J. Zhang, J. Feng, F. Li, D. Xue, et al., J. Nanopart. Res., 2013, 15, 1472.

31 J. Liu, W. Q. Cao, H. B. Jin, J. Yuan, D. Q. Zhang and M. S. Cao, J. Mater. Chem. C, 2015, 3, 4670.

32 B. Adohi, A. Mdarhri, C. Prunier, B. Haidar and C. Brosseau, J. Appl. Phys., 2010, 108, 074108.

33 H. Lv, Y. Guo, Z. Yang, Y. Cheng, L. P. Wang, B. Zhang, Y. Zhao, Z. J. Xu and G. Ji, J. Mater. Chem. C, 2017, 5, 491.
34 G. Wang, Z. Gao, S. Tang, C. Chen, F. Duan, S. Zhao, S. Lin, Y. Feng, L. Zhou and Y. Qin, ACS Nano, 2012, 6, 11009.

35 B. Adohi, V. Laur, B. Haidar and C. Brosseau, Appl. Phys. Lett., 2014, 104, 082902.

36 A. Dimiev, W. Lu, K. Zeller, B. Crowgey, L. C. Kempel and J. M. Tour, ACS Appl. Mater. Interfaces, 2011, 3, 4657.

37 J. Shang, Y. Zhang, L. Yu, X. Luan, B. Shen, Z. Zhang, et al., J. Mater. Chem. A, 2013, 1, 884.

38 B. Wen, M. S. Cao, M. M. Lu, W. Q. Cao, H. L. Shi, J. Liu, et al., Adv. Mater., 2014, 26, 3484.

39 Y. C. Qing, Y. Mu, Y. Y. Zhou, F. Luo, D. M. Zhu and W. C. Zhou, J. Eur. Ceram. Soc., 2014, 34, 2229.

40 H. L. Lv, G. B. Ji, X. H. Liang, H. Q. Zhang and Y. W. Du, J. Mater. Chem. C, 2015, 3, 5056.

41 Y. C. Qing, X. Wang, Y. Y. Zhou, Z. B. Huang, F. Luo and W. C. Zhou, Compos. Sci. Technol., 2014, 102, 161.

42 W. L. Song, M. S. Cao, M. M. Lu, S. Bi, C. Y. Wang, J. Liu, et al., Carbon, 2014, 66, 67.

43 W. L. Song, M. S. Cao, M. M. Lu, J. Liu, J. Yuan and L. Z. Fan, J. Mater. Chem. C, 2013, 1, 1846.

44 J. Feng, F. Z. Pu, Z. X. Li, X. H. Li, X. Y. Hu and J. T. Bai, Carbon, 2016, 104, 214.

45 X. H. Li, J. Feng, H. Zhu, C. H. Qu, J. T. Bai and X. L. Zheng, RSC Adv., 2014, 4, 33619.

46 W. Q. Cao, X. X. Wang, J. Yuan, W. Z. Wang and M. S. Cao, J. Mater. Chem. C, 2015, 3, 10017.

47 Y. C. Qing, J. Wang, H. Y. Wang, F. Luo and W. C. Zhou, RSC $A d v .$, 2016, 6, 80424. 